\title{
PARTICULARIDADES DO INQUÉRITO POLICIAL E SUA DISPENSABILIDADE
}

\author{
Gabriela Aparecida Pain, Amanda Vasconcelos Campos Gomes, Eduardo Buzetti Eustachio Bezerro \\ Universidade do Oeste Paulista - UNOESTE, curso de Direito, Presidente Prudente, SP. E-mail: \\ gabrielapain hp@outlook.com
}

\section{RESUMO}

Objetiva o presente estudo, apresentar o tema inquérito policial, bem como verificar a sua real necessidade e procedimento, através de sua origem histórica, com base nos princípios da ampla defesa e contraditório. Ademais, verificar suas competências, seus desdobramentos e exceções, explanar o problema e hipótese, firmando-se em seu procedimento e por fim, expor o posicionamento que melhor se adequa de acordo com a realidade atual.

Palavras-chave: Inquérito policial. Dispensabilidade. Processo Penal. Procedimento. Particularidades.

\section{PARTICULARITIES OF THE POLICE INQUIRY AND HIS DISPENSABILITY}

\section{ABSTRACT}

The purpose of this study is to present the subject of police investigation, as well as to verify its real necessity and procedure, through its historical origin, based on the principles of ample defense and contradictory. In addition, to verify its competences, its unfolding and exceptions, to explain the problem and hypothesis, establishing itself in its procedure and finally, to expose the positioning that best suits according to the current reality.

Keywords: Police investigation. Dispensability. Criminal proceedings. Procedure. Special features.

\section{INTRODUÇÃO}

O inquérito policial tem por finalidade a apuração da infração penal e informações acerca do fato criminoso, com todas as suas circunstâncias, além da elucidação da autoria do ilícito penal.

É por meio do inquérito policial que se desenvolve a atividade inicial persecutória estatal com destino a preparar um mínimo necessário de elementos informativos de convicção para subsidiar a propositura da futura e eventual ação penal em face da pessoa a quem tenha sido imputada a responsabilidade penal pela prática do fato delituoso ou contravencional.

Daí porque se pode assertar que o inquérito policial possibilita a dedução da pretensão punitiva em juízo, ou na expressão clássica do Direito, permite o jus persequendi in judicio.

Em geral, as informações sobre a prática criminosa e elementos que possam identificar o autor da infração penal são obtidos por meio do inquérito policial e após sua conclusão é que o expediente é encaminhado e permanece à disposição do titular da ação penal para o oferecimento de denúncia ou queixa crime.

Neste contexto, qual seria a necessidade do inquérito policial quando o titular da ação penal já dispuser de meios elucidadores da infração penal e sua autoria?

Assim, parte-se para discussões acerca do inquérito policial como peça meramente informativa, uma vez que analisando sua finalidade é possível reconhecer que o mesmo é dispensável.

Após breve reflexão, o estudo em tela, apresenta o tema inquérito policial, verifica a sua real necessidade e procedimento, expondo posicionamentos que o explicam. 
Trata-se de uma reflexão embasada em levantamento bibliográfico, doutrinas e legislação atual, uma vez que de acordo com as previsões legais, o procedimento do inquérito policial se apresenta de uma forma no que tange a sua dispensabilidade e de acordo com posicionamentos doutrinários de outra forma, partindo-se assim para a análise de suas particularidades.

Dessa forma, o presente artigo tem por objetivo mostrar os posicionamentos divergentes, expondo sólidos fundamentos.

\section{METODOLOGIA}

O presente estudo far-se-á por meio de levantamento bibliográfico, em doutrinas e legislação atual, realizando minuciosamente a respectiva leitura e fichamento, chegando-se a particularidades que serão discutidas por meio do emprego do método hipotético-dedutivo. Assim, visa construir o tema para que se encontrem possíveis respostas e soluções ao problema proposto, com o auxílio da lógica, confrontando e interpretando os dados coletados.

\section{RESULTADOS}

Ante a sua importância acadêmica e científica, o presente estudo contribuirá para reflexão junto à instituição de ensino no âmbito das ciências jurídicas, uma vez que se trata de tema ainda em discussão, trazendo o posicionamento majoritário de acordo com a realidade vivenciada no mundo jurídico, bem como aquele que em contrapartida, não se faz adotado pela maioria.

\section{DISCUSSÃO}

Partindo da concepção de Tourinho Filho (2010, p. 110) "Inquérito policial é um conjunto de diligências realizadas pela policia civil ou judiciária (como a denomina o CPP), visando a elucidar as infrações penais e sua autoria". Em outras palavras, o inquérito policial consiste em um procedimento administrativo de natureza inquisitória, instaurado e presidido pela autoridade policial, cujo objetivo é a elucidação da autoria da infração penal e da materialidade, compreendidas pelas informações sobre a existência do fato.

Cabe enfatizar que se trata de um procedimento uma vez que não há atenção aos princípios processuais da ampla defesa e contraditório e administrativo por ser gerenciado por autoridade policial, bem como a sua natureza inquisitória já que aqui o réu é tido como mero objeto, procedendo à autoridade como "bem entender".

Em suma, a natureza inquisitiva do inquérito tem sua base no sistema de persecução penal inquisitivo, o qual teve sua origem no cristianismo, em meados do século XII, onde concentrava ao juiz o chamado "actum trium personarum", ou seja, três funções sobre a mesma pessoa, quais sejam a de acusar, defender e decidir, não conferindo direitos ao acusado, ou seja, há época o réu não titularizava direitos, logo, não havia amparo pelos princípios da ampla defesa e contraditório, sendo considerado mero objeto.

Além de sua caracterização como um procedimento inquisitivo, o inquérito também toma por característica a obrigatoriedade quando se tratar de crime de ação pública incondicionada (art. $5^{\circ}$, inciso I, do CPP); sua sigilosidade (art. 20 do CPP), já que o sigilo se faz necessário para que realize as diligências pertinentes a elucidar o crime sem encontrar obstáculos que atrapalhariam a colheita de provas, com exceção ao Ministério Público, autoridade judiciária e advogado com a devida procuração; a formalidade de ser um documento escrito para atingir sua finalidade; a oficialidade já que precisa ser realizado por órgãos oficiais; a autoridade conforme previsão do art. $144, \S 4^{\circ}$, da Constituição Federal e ainda sua indisponibilidade conforme previsão no art. 17 do Código de Processo Penal, o qual prevê que "A autoridade policial não poderá mandar arquivar autos de inquérito". 
Assim, o inquérito policial terá por objetivo coleta de indícios e probabilidades de quem seja o autor da conduta ou como se deu a infração penal, viabilizando o ajuizamento da ação penal pelo Ministério Público, pelo ofendido ou por seu representante legal.

Referindo-se agora ao início do inquérito, deve-se analisar primeiramente a notitia criminis, a qual consiste no momento em que se toma conhecimento de um fato aparentemente criminoso pela autoridade policial de forma espontânea ou provocada, onde a partir dessa se dá início às investigações.

Segundo Tourinho Filho (2010, p. 119):

Essa notícia do crime pode ser de "cognição imediata", de "cognição mediata" e até mesmo de "cognição coercitiva". A primeira ocorre quando a Autoridade Policial toma conhecimento do fato infringente da norma por meio de suas atividades rotineiras. [...] notitia criminis de congnição mediata quando a Autoridade Policial sabe de fato por meio de requerimento da vítima ou de quem possa representa-la, requisição da Autoridade Judiciária ou do órgão do Ministério Público, ou mediante representação. Ela será de cognição coercitiva nas hipóteses de prisão em flagrante, visto que, nesses casos, ao tempo em que a Autoridade Policial toma conhecimento do fato criminoso, o seu autor lhe é apresentado, conduzido que foi sob coerção.

Partindo-se da notitia criminis, entra-se nas particularidades a respeito da instauração do inquérito policial, chegando ao seguinte questionamento: Como se dá inicio ao inquérito policial? Ora, dependerá para tanto, da natureza da ação cujo crime se refere, ou seja, trata-se de crime de ação penal pública condicionada, incondicionada ou crime de ação penal privada?

Leciona Mougenot Bonfim (2010, p. 145-147) que nos crimes de ação penal com iniciativa pública incondicionada, poderá o inquérito ser instaurado das seguintes formas:

a) De ofício (ex officio). Em se tratando de crimes para os quais a lei prevê que a ação penal seja de iniciativa pública incondicionada, a autoridade policial tem o dever de iniciar o inquérito policial sempre que tomar conhecimento do fato que possivelmente constituía crime [...] (grifo nosso)

b) Por meio de requisição. Tendo notícia de ocorrência de fato potencialmente criminoso, o Juiz ou o órgão do Ministério Público poderão dirigir à autoridade policial requisição para que seja instaurado inquérito com a finalidade de apurar esse fato [...] a requisição funcionaria como notitia criminis indireta.

c) Por meio de requerimento do ofendido ou de quem tenha qualidade para representa-lo [...]

d) Por força da "delatio criminis". Qualquer pessoa, ciente da prática de uma infração penal, pode noticiá-la à autoridade policial [...]

e) Mediante prisão em flagrante [...].

Já se tratando de crimes de ação penal com iniciativa pública condicionada, prevê o art. $5^{\circ}$ do Código de Processo Penal, em seu $\S 4^{\circ}$ que "O inquérito, nos crimes em que a ação pública depender de representação, não poderá sem ela ser iniciado". Assim, para se dar início a instauração do inquérito policial se fará necessária a representação do ofendido ou seu representante legal, ou ainda, a requisição do Ministro da Justiça (como por exemplo, nos casos previstos no art. $7^{\circ}, \S 3^{\circ}$, alínea $b$, do Código Penal e no art. 145 , parágrafo único, do mesmo 
diploma). Observa-se ainda a possibilidade de iniciar o inquérito em caso de prisão em flagrante do agente quanto da prática de crimes de ação penal pública condicionada, mas nesse caso, deverá ocorrer posteriormente ao flagrante a representação do titular do direito ofendido, dando para tanto a devida autorização.

Por fim, no caso de ação penal privada, prevê o art. $5^{\circ}$ do Código de Processo Penal, em seu $\S 5^{\circ}$ que "Nos crimes de ação penal privada, a autoridade policial somente poderá proceder a inquérito a requerimento de quem tenha qualidade para intentá-la", ou seja, dependerá do requerimento verbal ou escrito, reduzido a termo, seja pelo ofendido, seja por seu representante legal.

Instaurado o inquérito, caberá agora analisar os atos iniciais, os quais a autoridade irá proceder de acordo com o art. $6^{\circ}$, incisos I a III, do Código de Processo Penal, vejamos:

Logo que tiver conhecimento da prática da infração penal, a autoridade policial deverá:

I - dirigir-se ao local, providenciando para que não se alterem o estado e conservação das coisas, até a chegada dos peritos criminais;

II - apreender os objetos que tiverem relação com o fato, após liberados pelos peritos criminais;

III - colher todas as provas que servirem para o esclarecimento do fato e suas circunstâncias;

$[\ldots]$

Assim, caberá à autoridade realizar todas as diligências ali referidas, quando possível, pois dependerá da infração e do caso concreto, se dirigindo ao local dos fatos, providenciando desde logo o estado e conservação das coisas para a chegada dos peritos e também, realizar a apreensão dos instrumentos e demais objetos que tiveram relação com o fato que acompanharam o inquérito, bem como colher todas as provas como posto acima, podendo para tais diligências determinar a busca e apreensão, interceptação telefônica, observando para tanto as restrições constitucionais e a quebra de sigilo bancário, mediante autorização do juiz.

Prevê ainda o Código de Processo Penal em seu art. $6^{\circ}$, incisos IV a VII, os atos instrutórios do inquérito, quais sejam:

\section{$[\ldots]$}

IV - ouvir o ofendido;

V - ouvir o indiciado, com observância, no que for aplicável, do disposto no Capítulo III do Título VII, deste Livro, devendo o respectivo termo ser assinado por duas testemunhas que Ihe tenham ouvido a leitura;

$\mathrm{VI}$ - proceder a reconhecimento de pessoas e coisas e a acareações;

VII - determinar, se for caso, que se proceda a exame de corpo de delito e a quaisquer outras perícias;

VIII - ordenar a identificação do indiciado pelo processo datiloscópico, se possível, e fazer juntar aos autos sua folha de antecedentes;

IX - averiguar a vida pregressa do indiciado, sob o ponto de vista individual, familiar e social, sua condição econômica, sua atitude e estado de ânimo antes e depois do crime e durante ele, e quaisquer outros elementos que contribuírem para a apreciação do seu temperamento e caráter.

De acordo com a previsão sobredita, a autoridade deverá se possível, ouvir o ofendido, que fornecerá os elementos que melhor esclarecer o fato, bem como o indiciado, qualificando e identificando datiloscopicamente, quando possível, e ainda interroga-lo, observado o direito desse 
de ficar em silêncio, conforme previsto constitucionalmente no art. 5으, inciso LXIII, da Constituição Federal e ainda os casos que se tratar de indiciado menor.

Procederá também a acareações e ao reconhecimento de pessoas ou coisas, que deverão estar de acordo com as previsões contidas nos artigos 226, 227 e 228 do Código de Processo Penal, determinar a realização de exame de corpo de delito ou outras perícias e ainda, se de acordo com a moralidade e ordem pública, proceder à reprodução simulada dos fatos.

No indiciamento ainda, a autoridade policial deverá averiguar a vida pregressa do indiciado, ou seja, apresentar documento que conste se o criminoso é ou não reincidente, bem como as circunstâncias que sejam relevantes para a aplicação da pena.

Quando concluída a investigação, será feito relatório minuciosamente de tudo o que fora apurado no inquérito policial e assim, os autos serão encaminhados à autoridade competente, que dará vista ao Ministério Público.

Por fim, a conclusão do inquérito deverá observar o que estipula o Código de Processo Penal em seu art. 10, o qual prevê:

O inquérito deverá terminar no prazo de 10 (dez) dias, se o indiciado tiver sido preso em flagrante, ou estiver preso preventivamente, contado o prazo, nesta hipótese, a partir do dia em que se executar a ordem de prisão, ou no prazo de 30 (trinta) dias, quando estiver solto, mediante fiança ou sem ela.

Sendo que poderá ser solicitada ao Juiz a dilação do prazo sempre que o inquérito não estiver concluído dentro do prazo legal no caso de investigado solto, podendo ser prorrogado quantas vezes for necessário para se dar fim as investigações, devendo para tanto, ser a solicitação justificada.

É de se observar ainda, que há prazos especiais para conclusão do inquérito quando se tratar de prisão temporária (Lei n. 7.960/89), crimes hediondos (Lei n. 8.072/90), crimes alcançados pela Lei de Drogas n. 11.343 de 2006 e ainda, os prazos na justiça federal, os quais são prorrogáveis.

Superadas as particularidades acerca do inquérito policial, como sua finalidade e procedimento, há quem lecione a sua dispensabilidade no âmbito doutrinário, sustentando-a por ser o inquérito policial peça meramente informativa. Vejamos o que Tourinho Filho $(2010$, p. 114115) leciona:

O inquérito é peça meramente informativa. Nele se apuram a infração penal com todas as suas circunstâncias e respectiva autoria. Tais informações têm por finalidade permitir que o titular da ação penal. [...] possa exercer o jus persequendi in judicio, isto é, possa iniciar a ação penal. Se essa é a finalidade do inquérito, desde que o titular da ação penal (Ministério Público ou ofendido) tenha em mãos as informações necessárias, isto é, os elementos imprescindíveis ao oferecimento da denúncia ou queixa, é evidente que o inquérito será perfeitamente dispensável.

Assim, a partir desse entendimento, quando existirem provas suficientes da materialidade e autoria da prática delituosa, será o inquérito policial dispensável, ou seja, quando o titular da ação penal possuir elementos suficientes para a propositura da ação penal, não será necessário instaurar o inquérito policial.

\section{CONCLUSÃO}


Diante o exposto, conclui-se que embora o inquérito policial seja um procedimento necessário sob o ponto de vista de que por meio dele é que, regra geral, obtém-se a formação de um conjunto de elementos mínimos de convicção acerca da existência do fato e suas particularidades, bem como, sobre a autoria da infração penal, o inquérito é prescindível ao exercício da ação penal, visto que o titular da ação penal não está submetido à pré-existência do expediente administrativo-policial.

Entretanto, é de se observar que não se trata de uma dispensabilidade absoluta, já que na realidade atual, a partir da instauração do inquérito pela requisição do próprio Ministério Público ou de qualquer pessoa, os elementos informativos obtidos no inquérito e que foram documentados pela autoridade policial, formam um arcabouço de provas muitas vezes de valor inestimável não apenas para o ajuizamento da ação penal, mas para a efetiva demonstração em juízo sobre a responsabilidade penal do acusado.

\section{REFERÊNCIAS}

BONFIM, Edilson Mougenot. Curso de processo penal. 5. ed. São Paulo: Saraiva, 2010.

BRASIL. Código de processo penal. 17. ed. São Paulo: Saraiva, 2014.

Código penal. 17. ed. São Paulo: Saraiva, 2014.

Constituição (1998). Constituição da República Federativa do. Brasília: Senado

Federal, 1988.

REZENDE, Geibson; NEVES, Gustavo Bregalda; LOYOLA, Kheyder. Vade mecum OAB 1a Fase:

Doutrina. 3. ed. São Paulo: Rideel, 2013.

TOURINHO FILHO, Fernando da Costa. Manual de processo penal. 14. ed. São Paulo: Saraiva, 2010. 